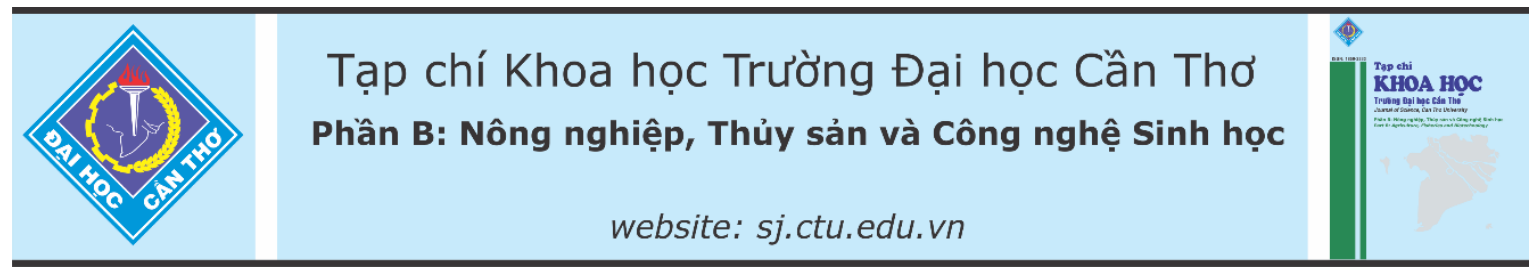

DOI:10.22144/ctu.jvn.2021.013

\title{
KHẢO SÁT HOẠT TÍNH KHÁNG VI SINH TỪ DỊCH CHIẾT VỎ MĂNG CỤT LÁI THIÊU (Garcinia mangostana)
}

\author{
Nguyễn Ngọc Ly, Vũ Hoàng Yến và Trần Ngọc Hùng* \\ Truờng Đại học Thủ Dầu Một \\ "Nguoòi chịu trách nhiệm bài viết:Trần Ngoc Hùng (email: hungtngoc@tdmu.edu.vn)
}

\section{Thông tin chung:}

Ngày nhận bài: 30/09/2020

Ngày nhận bài sủa: 28/12/2020

Ngày duyệt đăng: 27/02/2021

\section{Title:}

Antimicrobial activity from the extract of the pericarp of Lai Thieu mangosteen (Garcinia mangostana)

\section{Tù khóa:}

Kháng Staphylococcus aureus, vỏ măng cut Lái Thiêu, vòng kháng vi sinh vật

\section{Keywords:}

Anti-Staphylococcus aureus, Lai Thieu mangosteen pericarp, microbial inhibitory zone

\begin{abstract}
Lai Thieu mangosteen is the typical fruits of Vietnam; its pericarp is rich in various bioactive compounds which are good for health. The study was carried out to estimate the potential of using the Lai Thieu mangosteen pericarp to resist some microorganism species. The water extract of the mangosteen pericarp has a higher effectivity in anti-bacterial and antifungal activity than ethanol extract of the mangosteen pericarp. The inhibitive diametric zone of Bacillus sp., Staphylococcus aureus and Fusarium sp. of the water extract get 4,8 $\mathrm{mm}, 4,2 \mathrm{~mm}$ and 2,4 $\mathrm{mm}$, respectively. The extractive productivity of antibacterial compounds from mangosteen pericarp was highest when extracted in the ethanol/ water solution with the ratio of $30 / 70(\mathrm{v} / \mathrm{v})$, at $50^{\circ} \mathrm{C}$ for 5 hours. The diameter of inhibitory zone was $9.6 \mathrm{~mm}$. The MIC and MBC values for S. aureus of the mangosteen pericarp extract were 56.25 and $112.5 \mu \mathrm{g} / \mathrm{mL}$, respectively.
\end{abstract}

\section{TÓM TẮT}

Măng cut Lái Thiêu là trái cây đặc sản của Việt Nam; vỏ trái chưa nhiều hoạt chất có tác dụng tốt cho sức khỏe. Nghiên cưu được thực hiện nhằm đánh giá tiềm năng sủ dụng vỏ trái măng cut Lái Thiêu để kháng loài vi sinh vật. Dịch chiết nước vỏ măng cụt có khả năng kháng vi khuẩn và nấm bệnh thực vật tốt hơn so với khi chiết bằng ethanol. Đương kính vòng kháng Bacillus sp., Staphylococcus aureus và Fusarium sp. của dịch chiết nước lần luợt đạt 4,8; 4,2 và 2,4 mm. Hiệu quả thu nhận hoạt chất kháng khuẩn tù vỏ măng cut tốt nhất khi chiết trong dung dịch ethanol/nước với tỷ lệ 30/70, nhiệt độ chiết ở $50^{\circ} \mathrm{C}$ trong thời gian 5 giờ với đường kính vòng kháng Staphylococcus aureus đạt 9,6 $\mathrm{mm}$. Giá trị MIC và $M B C$ đối với $S$. aureus của vỏ măng cut chiết ở điều kiện thich hợp lần luợt đạt 56,25 và $112,5 \mu \mathrm{g} / \mathrm{mL}$.

\section{GIỚI THIỆU}

Măng cụt (Garcinia mangostana) là trái cây đặc sản nổi tiếng từ lâu đời của vùng đất Lái Thiêu Bình Dương. Là một trong những tỉnh trồng nhiều măng cụt nhất Việt Nam, diện tích măng cụt hiện nay tại Bình Dương đạt trên 1.009 ha với sản lượng hàng năm đạt 2.672 tấn (Cục Thống kê Bình Dương, 2018). Bên cạnh sự thơm ngon, bổ dưỡng của thịt quả, vỏ trái măng cụt còn chứa rất nhiều loại hoạt chất có giá trị tốt cho sức khỏe mà nổi bật nhất phải kể đến nhóm chất xanthone, chiếm gần $1 / 3$ tổng số các dẫn xuất xanthone được tìm thấy ở thực vật. Nhiều nghiên cứu cho thấy nhóm chất xanthone có tiềm năng về gây độc trên các dòng tế bào ung thư, kháng oxy hóa, kháng viêm và kháng khuẩn (Jennifer et al., 2019; Nguyễn Diệu Liên Hoa, 
2019). Các nghiên cứu trước đây tại Việt Nam tập trung nhiều vào việc phân lập các hoạt chất có trong vỏ măng cụt và kháng một số dòng ung thư. Năm 2009, Nguyễn Trí Hiếu và $c t v$. đã phân lập được $\beta$ mangostin và $3-O$-methyl-normangostin từ vỏ trái măng cụt. Đỗ Thanh Xuân và ctv. (2011) cũng đã cô lập được $\alpha$-mangostin và $\gamma$-mangostin từ vỏ trái măng cụt. Những nghiên cứu về khả năng kháng một số dòng vi khuẩn gây bệnh cũng đã được thực hiện trên những hợp chất tinh sạch được từ vỏ trái măng cụt (Đỗ Thanh Xuân và ctv., 2011; Đỗ Thị Tuyên và ctv., 2012). Hoạt chất $\alpha$-mangostin cũng đã được nghiên cứu bổ sung vào nước xúc miệng và thuốc chống ung thư (Hoàng Đức Hậu và ctv., 2017; Mai Thị Hiên, 2011). Nghiên cứu này tập trung vào việc đánh giá hoạt tính kháng Staphylococcus aureus của vỏ trái măng cụt trồng ở khu vực thị xã Thuận An, tỉnh Bình Dương. Trên cơ sở đó, các thông số của quá trình chiết như tỷ lệ ethanol/nước; thời gian và nhiệt độ chiết; nồng độ ức chế tối thiểu (MIC) và nồng độ diệt khuẩn tối thiểu $(\mathrm{MBC})$ được khảo sát. Việc tận dụng nguồn vỏ trái măng cụt để tạo ra các sản phẩm có tính kháng khuẩn sẽ giúp nâng cao giá trị kinh tế của loại trái cây đặc sản này cho địa phương.

\section{THỰC NGHIỆM}

\subsection{Nguyên liệu}

Vỏ măng cụt được thu nhận tại thị xã Thuận An, tỉnh Bình Dương; vỏ tươi, không có biểu hiện sâu bệnh; vỏ được phơi khô, xay nhuyễn thành bột mịn.

Các loài nấm bệnh thực vật thử nghiệm bao gồm Colletotrichum gloeosporioides, Fusarium sp. được phân lập từ các loại cây trồng bị bệnh, do phòng thí nghiệm Sinh học ứng dụng, Trường Đại học Thủ Dầu Một cung cấp.

Các loài vi khuẩn thử nghiệm bao gồm Bacillus sp.; E. coli; Staphylococcus aureus; Vibrio paraheamolyticus do phòng thí nghiệm Sinh học ứng dụng, Trường Đại học Thủ Dầu Một cung cấp.

\subsection{Phương pháp tiến hành}

2.2.1. Đánh giá khả năng kháng vi sinh vật của vỏ măng cut

Thí nghiệm đánh giá trên 2 loại dung môi chiết khác nhau là ethanol 99,9\% và nước, với 12 nghiệm thức (mỗi loại dung môi chiết được đánh giá khả năng kháng với 4 loài vi khuẩn và 2 loài nấm bệnh thực vật), mỗi nghiệm thức lặp lại 5 lần.

Một kilogram vỏ măng cụt tươi được sấy khô ở nhiệt độ $50^{\circ} \mathrm{C}$ trong 4 ngày và xay nhuyễn; lượng bột thu được là $218 \mathrm{~g}$, độ ẩm bột vỏ măng cụt $9,0 \pm$
$0,3 \%$. Bột vỏ trái măng cụt được ly trích các chất hòa tan trong ethanol ở tỷ lệ pha loãng 10 lần. Ngâm trong thời gian 24 giờ ở nhiệt độ $50^{\circ} \mathrm{C}$, thu dịch chiết bằng cách ly tâm ở tốc độ 5.000 vòng/phút trong thời gian 5 phút; cô cạn dịch chiết và ghi nhận khối lượng cao ethanol. Cân $0,1 \mathrm{~g}$ cao, hòa tan trong $10 \mathrm{~mL}$ nước cất vô trùng; lọc dịch qua film lọc $0,22 \mu \mathrm{m}$.

Đối với nước, bột vỏ măng cụt được ly trích với tỷ lệ pha loãng 10 lần, trong 2 giờ ở nhiệt độ $35^{\circ} \mathrm{C}$; lọc qua giấy lọc rồi tiếp tục lọc qua film lọc vô trùng kích thước lỗ $0,22 \mu \mathrm{m}$. Giếng đối chứng được thực hiện với nước cất ở cùng thể tích.

\section{Khả năng kháng nấm bệnh thực vật}

Hút $0,1 \mathrm{~mL}$ các loại dịch khảo sát cho vào các giếng đã đục sẵn trên môi trường PGA (Potato Glucose Agar) có chứa các chủng nấm bệnh thực vật đã được cấy trước 2 ngày với đường kính vòng tăng trưởng đạt $2 \mathrm{~cm}$ đối với Fusarium $\mathrm{sp}$. và $2,5 \mathrm{~cm}$ đối với Collectotrichum gloeosporioides. Ủ 24 giờ ở nhiệt độ phòng, đo kích thước vòng kháng nấm của các loại dịch chiết. Giếng đối chứng âm chứa nước cất vô trùng (Mounyr et al., 2016).

\section{Khả năng kháng vi khuẩn của vỏ măng cụt}

Các chủng vi khuẩn kiểm định được nuôi cấy trên môi trường TSB (Tryptone Soya Broth) trong thời gian 24 giờ, mật độ vi khuẩn được điều chỉnh $10^{7} \mathrm{CFU} / \mathrm{mL}$. Thêm $0,1 \mathrm{~mL}$ các loại dịch khảo sát cho vào các giếng đã đục sẵn trên môi trường TSA (Tryptone Soya Agar) đã trải các chủng vi khuẩn kiểm định. Ủ 24 giờ ở nhiệt độ phòng; đo kích thước vòng kháng khuẩn của các loại dịch chiết. Giếng đối chứng chứa nước cất vô trùng (Mounyr et al., 2016).

2.2.2. Anh huơong các yếu tố đến khả năng thu nhận hoạt chất kháng Staphylococcus aureus tù vỏ măng cụt

Ảnh hưởng của tỷ lệ dung môi chiết được khảo sát với 6 nghiệm thức, lặp lại 3 lần, bằng cách ngâm $10 \mathrm{~g}$ bột vỏ trái măng cụt trong $90 \mathrm{~mL}$ dung dịch có tỷ lệ ethanol/nước thay đổi: 100/0;40/60;30/70; $20 / 80 ; 10 / 90$ và $0 / 100$. Sau 2 giờ, lắc ở nhiệt độ $50^{\circ} \mathrm{C}$, thu nhận dịch chiết; xác định hoạt tính kháng Staphylococcus aureus của dịch chiết. Các giếng đối chứng được thực hiện với dung dịch có cùng tỷ lệ ethanol. Các nghiệm thức được lặp lại 3 lần.

Dịch chiết tiếp tục được cô cạn dung môi ở nhiệt độ $50^{\circ} \mathrm{C}$. Hiệu suất thu nhận cao chiết $(\%)=$ khổi lượng cao/ khối lượng bột vỏ măng cụt x 100 .

Ảnh hưởng của thời gian và nhiệt độ chiết được khảo sát với 24 nghiệm thức, mỗi nghiệm thức lặp 
lại 3 lần, bằng cách ly trích bột vỏ măng cụt ở các nhiệt độ khác nhau: $30^{\circ} \mathrm{C} ; 40^{\circ} \mathrm{C} ; 50^{\circ} \mathrm{C}$ và $60^{\circ} \mathrm{C}$ trong thời gian từ 1 đến 6 giờ; ly trích dịch và xác định hiệu quả kháng Staphylococcus aureus; giếng đối chứng được thực hiện với dung dịch có tỷ lệ ethanol/nước là 30/70.

2.2.3. Xác định nồng độ úc chế tối thiểu (MIC) và nồng độ diệt khuẩn tối thiểu $(M B C)$ của dịch chiết vỏ măng cut

Nồng độ ức chế tối thiểu (MIC, minimum inhibitory concentration) là nồng độ thấp nhất trong dãy thử nghiệm có thể ức chế sự phát triển của vi khuẩn, dung dịch nuôi cấy có màu xanh khi thêm 1 $\mathrm{mL}$ dung dịch resazurin $0,01 \%$. Trong khi đó, các ống nghiệm có sự phát triển của vi khuẩn sẽ có màu hồng khi thêm resazurin $0,01 \%$ (Mounyr et al., 2016).

Nồng độ diệt khuẩn tối thiểu $(\mathrm{MBC}$, minimum bactericidal concentration) là nồng độ thấp nhất trong dãy cao chiết thử nghiệm có thể tiêu diệt 99,9\% vi khuẩn trong ống nghiệm. Các ống nghiệm ở nồng độ không làm đồi màu dung dịch resazurin được xác định mật độ vi khuẩn trong dịch nuôi bằng phương pháp trải đĩa trên môi trường TSA; đếm số khuẩn lạc mọc sau 24 giờ ủ ở $35^{\circ} \mathrm{C}$ (Mounyr et al., 2016).

Dịch chiết vỏ măng cụt thu được ở điều kiện thích hợp được cô cạn thành cao; cân $0,1 \mathrm{~g}$ cao hòa tan trong dung dịch DMSO (Dimethyl sulfoxide) rồi định mức thành $10 \mathrm{~mL}$ (dung dịch gốc). Dung dịch gốc được lọc qua film lọc $0,22 \mu \mathrm{m}$ rồi pha loãng thành dãy có nồng độ giảm dần: $1 / 2 ; 1 / 4 ; 1 / 8 ; 1 / 16$; $1 / 32$ và $1 / 64$ trong dung dịch DMSO. Dịch lọc được cô cạn để xác định khối lượng cao tan trong DMSO. Vi khuẩn Staphylococcus aureus được nuôi cấy trên môi trường TSB trong 24 giờ và pha loãng sao cho mật số đạt $10^{7} \mathrm{CFU} / \mathrm{mL}$. Thí nghiệm được tiến hành lặp lại 3 lần với 8 nghiệm thức, bao gồm nghiệm thức đối chứng dương chứa $0,5 \mathrm{~mL}$ dịch vi khuẩn, $2,0 \mathrm{~mL}$ môi trường $\mathrm{TSB}$ và $2,5 \mathrm{~mL}$ dung dịch DMSO; nghiệm thức đối chứng âm chứa $0,5 \mathrm{~mL}$ nước cất, $2,0 \mathrm{~mL}$ môi trường $\mathrm{TSB}$ và $2,5 \mathrm{~mL}$ dung dịch DMSO; các nghiệm thức thí nghiệm chứa 0,5 $\mathrm{mL}$ huyền phù vi khuẩn, $2,0 \mathrm{~mL}$ môi trường $\mathrm{TSB}$ và $2,5 \mathrm{~mL}$ dung dịch cao chiết có tỷ lệ pha loãng giảm dần $(1 / 2 ; 1 / 4 ; 1 / 8 ; 1 / 16 ; 1 / 32$ và $1 / 64)$; giữ các ống nghiệm ở nhiệt độ $35^{\circ} \mathrm{C}$ trong 24 giờ.

\subsection{Xử lý thống kê}

Xử lý thống kê ANOVA bằng phần mềm Stargraphic Centurion 15. So sánh trung bình bằng kiểm định one-way ANOVA.

\section{KẾT QUẢ VÀ BÀN LUẬN}

\subsection{Khả năng kháng vi sinh vật của vỏ măng cụt}

Bột vỏ măng cụt được ly trích hoạt chất trong nước và ethanol. Đường kính vòng kháng vi khuẩn và nấm gây bệnh thực vật của dịch chiết được thể hiện trong hình 1.

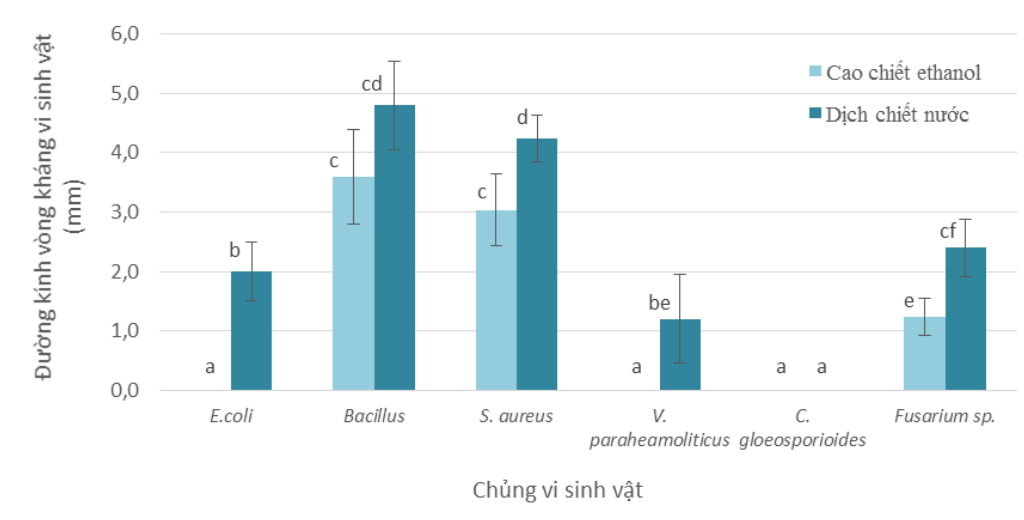

Hình 1. Khả năng kháng một số chủng vi sinh vật của dịch chiết vỏ măng cụt

Các ký tự khác nhau trên các cột thể hiện sự sai khác ở độ tin cậy 95\% (p<0,05).

Hoạt tính kháng vi sinh vật trong vỏ măng cụt thay đổi tùy theo loại dung môi ly trích. Ly trích với nước cho hiệu quả kháng vi sinh vật cao hơn so với ethanol, trong khi các giếng đối chứng không khi nhận vùng kháng. Khả năng kháng nấm gây bệnh thực vật của dịch chiết vỏ măng cụt không cao, đường kính vòng kháng trên nấm Fusarium sp chỉ đạt 2,4 mm đối cao dịch chiết nước. Hiệu quả kháng khuẩn thể hiện trên các chủng Gram dương như Bacillus và Staphylococcus tốt hơn so với Gram âm như E. coli và Vibrio paraheamolyticus. Đường kính vòng kháng Bacillus và $S$. aureus của dịch chiết nước vỏ măng cụt lần lượt đạt 4,8 và $4,2 \mathrm{~mm}$. Kết quả kháng hai loại vi khuẩn này cũng được Đỗ Thị 
Tuyên và ctv. (2012) ghi nhận. Hoạt chất amangostin ở nồng độ $50 \mu \mathrm{g} / \mathrm{mL}$ cho vòng kháng Bacillus subtilis và Staphylococcus aureus đạt lần lượt 7 và $5 \mathrm{~mm}$ (Srinivasan et al., 2017), Staphylococcus aureus là tác nhân gây ra nhiều bệnh nhiễm trùng và viêm phổi. Các đặc điểm kháng $S$. aureus của hoạt chất chiết từ vỏ măng cụt được xác định nhằm định hướng ứng dụng sản phẩm vào lĩnh vực bảo vệ sức khỏe, nâng cao giá trị sử dụng của loại trái cây đặc sản Bình Dương.

3.2. Ảnh hưởng của các yếu tố đến khả năng thu nhận hoạt chất kháng Staphylococcus aureus từ vỏ măng cụt

\subsubsection{Anh hương của tỷ lệ dung môi chiết}

Kết quả đánh giá trên vi khuẩn $S$. aureus cho thấy các hoạt chất chiết trong nước có hiệu quả kháng tốt hơn so với trong ethanol. Thí nghiệm được thực hiện với sự thay đổi tỷ lệ ethanol/nước trong dung dịch chiết. Hiệu quả kháng khuẩn của dịch chiết và hiệu suất thu nhận cao chiết được thể hiện trong Hình 2.

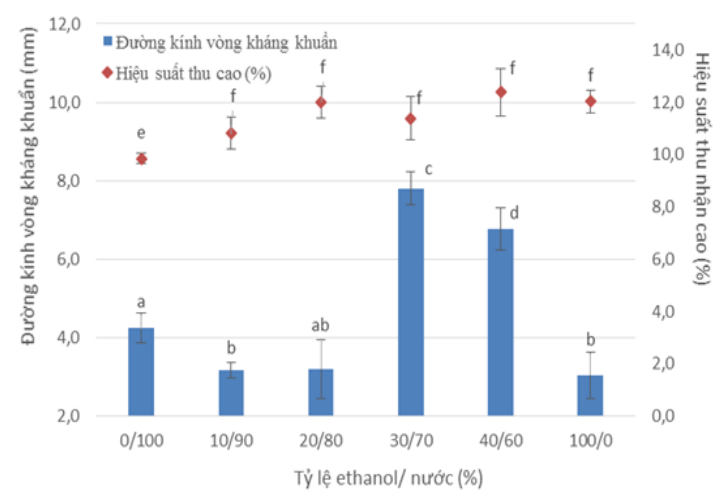

Hình 2. Ảnh hưởng của tỷ lệ dung môi chiết đến khả năng kháng khuẩn của vỏ măng cụt

Các ký tự khác nhau biểu thị mức độ sai khác ở độ tin cây $95 \%(p<0,05)$.

Hiệu quả kháng khuẩn thay đổi đáng kể theo tỷ lệ ethanol trong dung môi chiết, trong khi hiệu suất thu nhận cao trong các nghiệm thức có bổ sung ethanol không khác biệt, đạt từ 10,82\% đến $12,39 \%$ so với bột vỏ măng cụt khô. Sử dụng dung môi chiết với tỷ lệ ethanol/nước là 30/70 cho thấy hiệu quả hòa tan các hoạt chất kháng $S$. aureus tốt nhất, với hiệu suất thu nhận cao chiết đạt $11,39 \%$ và đường kính vòng kháng $S$. aureus của dịch chiết đạt 7,8 $\mathrm{mm}$. Khác biệt về mặt thống kê so với đường kính vòng kháng của các nghiệm thức khác ở độ tin cậy $95 \%(\mathrm{p}<0,05)$ (hình 2$)$. Kết quả này cho thấy các hoạt chất kháng $S$. aureus từ vỏ quả măng cụt Lái
Thiêu có thể thuộc nhóm xanthone, hòa tan tốt trong hỗn hợp dung môi có độ phân cực trung bình, là nhóm hoạt chất kháng khuẩn đặc trưng của các cây thuộc họ Garcinia (Negi et al., 2013). Nghiên cứu trước đây cũng cho thấy hợp chất xanthone từ lớp vỏ trái măng cụt có hiệu quả kháng tốt với dòng vi khuẩn Porphyromonas gingivalis (Jennifer et al., 2019).

\subsubsection{Anh hưởng của nhiệt độ và thời gian chiết}

Thời gian chiết không có ảnh hưởng không nhiều đến khả năng kháng $S$. aureus của dịch chiết trong khi nhiệt độ chiết ở $60^{\circ} \mathrm{C}$ cho hiệu quả kháng khuẩn giảm đáng kể so với khi chiết ở các khoảng nhiệt độ thấp hơn. Nhiệt độ cao có thể gia tăng sự hòa tan của các chất vào dung môi nhưng có thể tác động tới cấu trúc phân tử, làm giảm hoạt tính sinh học của các chất. Kết quả thí nghiệm cho thấy vỏ măng cụt chiết ở $50^{\circ} \mathrm{C}$ trong thời gian 5 giờ có đường kính vòng kháng $S$. aureus tốt nhất, đạt $9,6 \mathrm{~mm}$, khác biệt về mặt thống kê so với các nghiệm thức còn lại ở độ tin cậy $95 \%(\mathrm{p}<0,05)$, thời gian ngâm chiết lâu hơn không đem lại sự gia tăng hiệu quả kháng khuẩn. Kết quả này có thể do các hoạt chất kháng Staphylococcus aureus trong vỏ măng cụt hòa tan nhanh trong hệ dung môi 30 ethanol/ 70 nước, nên thời gian ngâm lâu hơn không làm thay đổi khả năng kháng khuẩn của dịch chiết. Hiệu quả ly trích có thể nâng cao hơn với phương pháp chiết ngấm kiệt. Cao vỏ măng cụt thu được khi chiết với hỗn hợp dung môi chứa $30 \%$ ethanol và $70 \%$ nước, nhiệt độ $50^{\circ} \mathrm{C}$ trong thời gian 5 giờ được sử dụng cho khảo sát tiếp theo.

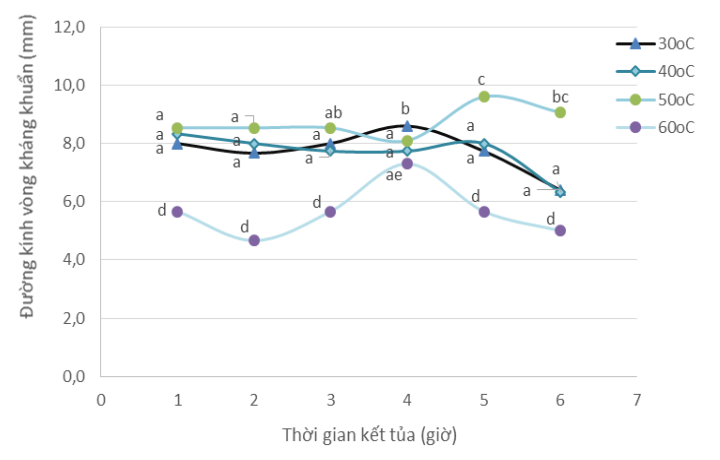

Hình 3. Ảnh hưởng của nhiệt độ và thời gian chiết đến khả năng kháng khuẩn của vỏ măng cụt

Các ký tụ khác nhau biểu thị mức độ sai khác ở độ tin cây $95 \%(p<0,05)$.

\subsection{Nồng độ ức chế tối thiểu và nồng độ diệt} khuẩn tối thiểu của dịch chiết vỏ măng cụt

Hòa tan 100 mg cao vỏ măng cụt với $10 \mathrm{~mL}$ nước cất vô trùng; $5 \mathrm{~mL}$ dịch lọc qua film được sấy khô. 
Hàm lượng hòa cao tan trong DMSO thực tế đạt 9 $\mathrm{mg} / 5 \mathrm{~mL}$. Dịch lọc qua film được pha loãng thành dãy nồng độ giảm dần để khảo sát chỉ số MIC và MBC. Kết quả thí nghiệm thể hiện trong Bảng 1.

\section{Bảng 1. Mật số Staphylococcus aureus trong môi trường có bổ sung dịch chiết vỏ măng cụt}

\begin{tabular}{cccc}
\hline $\begin{array}{c}\text { Tỷ lệ pha loãng } \\
\text { dịch cao gốc }\end{array}$ & $\begin{array}{c}\text { Nồng độ cao } \\
(\boldsymbol{\mu g} / \mathbf{m L})\end{array}$ & $\begin{array}{c}\text { Màu dịch nuôi cấy khi } \\
\text { thêm reazurin } \mathbf{0 , 0 1 \%}\end{array}$ & $\begin{array}{c}\text { Mật độ Staphylococcus } \\
\text { aureus }(\mathbf{C F U} / \mathbf{~ m L})\end{array}$ \\
\hline $\begin{array}{c}\text { Dịch tăng sinh ban } \\
\text { đầu }\end{array}$ & - & - & $1,2 \times 10^{7}$ \\
0 & 0 & Hồng & $1,8 \times 10^{9}$ \\
$1 / 8$ & 112,50 & Xanh & $1,5 \times 10^{6}$ \\
$1 / 16$ & 56,25 & Xanh tím & $1,6 \times 10^{7}$ \\
$1 / 32$ & 28,12 & Hồng & $7,8 \times 10^{8}$ \\
\hline
\end{tabular}

Ở nghiệm thức sử dụng dịch cao có độ pha loãng $1 / 16$ tương ứng với $56,25 \mu \mathrm{g} / \mathrm{mL}$, dịch nuôi cấy chuyển màu xanh tím khi bố sung resazurin $0,01 \%$, mật độ $S$. aureus của nghiệm thức này cũng xấp xỉ với dịch tăng sinh ban đầu (Bảng 1). Kết quả này cho thấy nồng độ ức chế tối thiểu vi khuẩn $S$. aureus của cao vỏ măng cụt đạt khoảng $56,25 \mu \mathrm{g} / \mathrm{mL}$. Các nghiên cứu trước đây về khả năng kháng khuẩn của vỏ măng cụt chủ yếu thực hiện với các hoạt chất tinh khiết như công bố của Đỗ Thị Tuyên và ctv. (2012) cho thấy hoạt chất $\alpha$-mangostin có nồng độ ức chế tối thiểu với Staphylococcus aureus là $15 \mu \mathrm{g} / \mathrm{mL}$ ). Nghiên cứu này đề xuất một giải pháp ly trích cao tổng đơn giản với hệ dung môi ethanol/nước, có hiệu quả ức chế Staphylococcus aureus cao. Trong khi đó, nồng độ diệt khuẩn (MBC) của cao vỏ măng cụt đối với Staphylococcus aureus đạt 112,5 $\mu \mathrm{g} / \mathrm{mL}$, mật độ vi khuẩn giảm $99,91 \%$ so với nghiệm thức không bổ sung cao chiết. So với nồng độ diệt khuẩn tối thiểu đối với $S$. aureus của cao ethyl acetate lá dâm bụt, đạt $200 \mu \mathrm{g} / \mathrm{mL}$ (Lương Thị Mỹ Ngân và ctv., 2016), cao chiết của vỏ măng cụt cho khả năng kháng $S$. aureus tốt hơn. Nghiên cứu trước đây của Tadtong et al. (2009) đã cho thấy các nhóm carbonyl của hợp chất xanthone từ vỏ quả măng cụt có thể phản ứng với các amino acid trên các phân tử protein màng, các enzyme ngoại bào và các protein của vách, qua đó phá hủy các cấu trúc polymer sinh học của vi khuẩn. Kết quả đề tài là cơ sở để tận dụng nguồn phế liệu vỏ trái măng cụt làm các sản phẩm diệt khuẩn bảo vệ sức khỏe như kem đánh răng, nước xúc miệng, gel rửa tay.

\section{KẾT LUẬN}

Dịch chiết nước vỏ măng cụt trồng tại Bình Dương có khả năng kháng nhiều loại vi khuẩn và nấm bệnh thực vật tốt hơn so với khi chiết bằng ethanol. Hiệu quả thu nhận hoạt chất kháng khuẩn từ vỏ măng cụt tốt nhất khi chiết trong hỗn hợp dung môi chứa $30 \%$ ethanol và $70 \%$ nước. Đường kính vòng kháng Staphylococcus aureus đạt 9,6 mm khi chiết ở $50^{\circ} \mathrm{C}$ trong thời gian 5 giờ. Giá trị $\mathrm{MIC}$ và $\mathrm{MBC}$ đối với $S$. aureus của vỏ măng cụt chiết ở điều kiện thích hợp lần lượt đạt 56,25 và $112,5 \mu \mathrm{g} / \mathrm{mL}$.

\section{LỜI CẢM ƠN}

Nhóm tác giả xin chân thành cảm ơn sự hỗ trợ kinh phí của Trường Đại học Thủ Dầu Một trong khuôn khổ đề tài nghiên cứu khoa học cấp cơ sở với mã số DT.20.1-103.

\section{TÀI LIỆU THAM KHẢO}

Cục Thống kê Bình Dương (2018). Niên giám thống kê Bình Dương 2018. Nxb. Thanh Niên.

Đỗ Thanh Xuân, Trần Văn Quốc, Nguyễn Ngọc Hạnh và Phùng Văn Trung (2011). Phân lập hai hợp chất tinh khiết từ vỏ trái măng cụt (Garcinia mangstana L.) và thử hoạt tính của chúng. Tạp chí Khoa hoc trưòng Đại hoc Cần Tho, $18 a$, 153-160.

Đỗ Thị Tuyên, Mai Thị Hiên, Phí Thị Mơ, Nguyễn Thị Ngọc Dao \& Quyền Đình Thi (2012).

Nghiên cứu hoạt tính kháng khuẩn của hoạt chất a-magostin tách ra từ vỏ quả măng cụt Garcinia mangostana L.. Tạp chí Khoa họ và Công nghệ, 50(1), 21-28.

Hoàng Đức Hậu, Võ Viết Cường, Nguyễn Vũ Anh và Nguyễn Thị Mai Phương (2017). Đánh giá tác dụng kháng sâu răng của nước súc miệng chứa a-mangostin. Tap chi Khoa hoc và Công nghẹ Nhiệt đói, 13, 163-169.

Jennifer, W., Dian, A. W., \& Febriastuti, C., (2019). Antibacterial Effect of Xanthone from Mangosteen Pericarp Extract (Garcinia mangostana Linn.) against Porphyromonas gingivalis. Journal of International Dental and Medical Research, 12(1), 19-21.

Lương Thị Mỹ Ngân, Lê Thị Kim Lan, Nguyễn Thị Thùy Linh, Nguyễn Ngọc Quý, Lê Thị Thanh Loan, Trương Thị Huỳnh Hoa \& Trần Trung Hiếu (2018). Nghiên cứu hoạt tính kháng khuẩn của cao chiết lá và hoa dâm bụt Hibiscus rosasinensis L. lên Proteus mirabilis, Pseudomonas aeruginosa và Klebsiella 
pneumoniae. Tap chí phát triển khoa học và công nghệ : Chuyên san Khoa học Tụ nhiên, 2(1), 19-26.

Lương Thị Mỹ Ngân, Nguyễn Thị Thuỳ Linh, Nguyễ் Ngọc Quý, Phạm Thị Ngọc Huyền, Trương Thị Huỳnh Hoa, Trần Trung Hiếu \& Phạm Thành Hổ (2016). Nghiên cứu hoạt tính kháng Staphylococcus aureus và Klebsiella pneumoniae của cao chiết lá dâm bụt (Hibiscus rosasinensis L.). Tạp chí Phát triển Khoa học và Công nghẹ, 19(5), 84-94.

Mai Thị Hiên (2011). Nghiên cúu quy trình công nghệ tách chiết và tinh chế Mangostin trong vỏ quả măng cưt Garcinia mangostnan L. làm thuốc hỗ trơ điều trị ung thu. Luận văn thạc sĩ ngành sinh học thực nghiệm. Trường đại học Khoa học Tự nhiên Hà Nội.

Mounyr B., Moulay S. and Saad K. I. (2016). Methods for in vitro evaluating antimicrobial activity: A review. Journal of Pharmaceutical Analysis, 6, 71-79.

Narasimhan, S., Maheshwaran, S., Abu-Yousef, I. A., Majdalawieh, A. F., Rethavathi, J., Das, P.
E., \& Poltronieri, P. (2017). Anti-bacterial and anti-fungal activity of xanthones obtained via semi-synthetic modification of $\alpha$-mangostin from Garcinia mangostana. Molecules, 22(2), 275.

Negi, J. S., Bisht, V. K., Singh, P., Rawat, M. S. M. and Joshi, G. P. (2013). Naturally Occurring Xanthones: Chemistry and Biology, Journal of Applied Chemistry, 2013, Article ID 621459. http://dx.doi.org/10.1155/2013/621459

Nguyễn Diệu Liên Hoa, Hà Diệu Ly và Nguyễn Thị Lệ Thu (2019). Thành phần hóa học và hoạt tính sinh hoc của ho măng cut (Guttiferae). Nxb. Đại học quốc gia tp. Hồ Chí Minh.

Nguyễn Trí Hiếu, Hà Diệu Ly, Phạm Đình Hùng \& Nguyễn Diệu Liên Hoa (2009). Cô lập và xác định cấu trúc năm dẫn xuất xanthol từ vỏ trái măng cụt (Garcinia mangostana). Tạp chí Duợc hoc, 400(8), 18-22.

Tadtong, S., Viriyaroj, A., Vorarat, S., Nimkulrat, S., Suksamrarn, S. (2009). Antityrosinase and antibacterial activities of mangosteen pericarp extract. J. Heal Res, 23(2), 99-102. 